\title{
Scientometrics \\ Russian Index of Science Citation: Overview and Review \\ --Manuscript Draft--
}

Manuscript Number:

Full Title:

Article Type:

Keywords:

Corresponding Author:

Corresponding Author Secondary Information:

Corresponding Author's Institution:

Corresponding Author's Secondary Institution:

First Author:

First Author Secondary Information:

Order of Authors:

Olga Moskaleva, Ph.D.

Vladimir Pislyakov, Ph.D.

Ivan Sterligov

Mark Akoev

Svetlana Shabanova

Order of Authors Secondary Information:

Funding Information:

Abstract:

SCIM-D-18-00056

S.I. : ISSI-2017

Vladimir Pislyakov, Ph.D.

Olga Moskaleva, Ph.D.
Russian Index of Science Citation: Overview and Review

national citation indexes; Russia; Russian Index of Science Citation; eLIBRARY.RU

National Research University Higher School of Economics

Moscow, RUSSIAN FEDERATION

National Research University Higher School of Economics

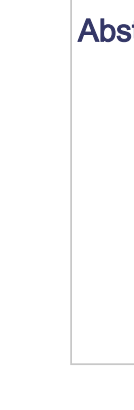

In early 2016 a new database was launched on the Web of Science platform Russian Science Citation Index (RSCl). The database is free to all Web of Science subscribers except those from the post-Soviet states. This database includes papers from 652 selected Russian journals and is based on the data from national citation index - Russian Index of Science Citation (RISC). RISC was launched in 2005 but it is scarcely known to the English-language audience. The paper describes the history, current structure and user possibilities of RISC. We focus on the novel features of RISC which are crucial to bibliometrics and are unavailable in the international citation indexes. 


\begin{abstract}
In early 2016 a new database was launched on the Web of Science platform-Russian Science Citation Index (RSCI). The database is free to all Web of Science subscribers except those from the post-Soviet states. This database includes papers from 652 selected Russian journals and is based on the data from national citation index Russian Index of Science Citation (RISC). RISC was launched in 2005 but it is scarcely known to the Englishlanguage audience. The paper describes the history, current structure and user possibilities of RISC. We focus on the novel features of RISC which are crucial to bibliometrics and are unavailable in the international citation indexes.
\end{abstract}

\title{
Introduction. History and main objectives of RISC
}

Modern research evaluation increasingly implies the bibliometric analysis of research output of scientists, organizations, etc., which is traditionally performed using the Web of Science, Scopus or Google Scholar data (Wouters et al. 2015). However, the national and regional scholarly literature are often poorly covered by these databases. In Russia, estimations show that less than $10 \%$ of all publications by Russian scientists are covered by Web of Science or Scopus (Gennadiy Eremenko, personal communication) and there is a strong need to fill this gap (Tretyakova 2015). Coverage is especially poor for Russian publications in social sciences and humanities, but also in medicine and engineering, mainly because the majority of these publications are in Russian. In 2005, the Ministry of Education and Science of Russia has initiated a project primarily aimed at creating a comprehensive bibliographic/citation database of Russian scholarly publishing, Russian Index of Science Citation (RISC). Such a database could greatly enhance both scholarly literature search and bibliometric research evaluation for Russian scholars and research managers.

Unlike Web of Science or Scopus, RISC from the very beginning was integrated with a full text platform Scientific Electronic Library (its trademark eLIBRARY.RU is used further in the paper). eLIBRARY.RU has started as a full text database of scholarly literature for grant holders of Russian Basic Research Foundation (RFBR) and its main purpose was to provide Russian scientists with access to papers from leading international academic journals (Eremenko 2003). Later it began offering both free and paid access to a broad range of Russian scholarly publishers. After a prolonged period of governmental support both RISC and eLIBRARY.RU 
nowadays are owned by a Russian company OOO Scientific Electronic Library and are operated as for-profit entities with no ties to the Russian Government or RFBR.

In general, the need for creating national citation indexes are explained by Pislyakov (2007). There are plenty of examples and stories of implementation of such databases for different countries. For example, in China not one but several national indexes were created (Jin and Wang 1999; Su et al. 2014; Wu et al. 2004; Ye 2014). There are also cases in India (Yadav and Yadav 2014), Japan (Negishi et al. 2004), etc. Other stories were less successful, the Serbian case was presented at previous ISSI conferences (Šipka 2005; Pajić 2015).

Unlike Web of Science and Scopus, until recently there were no strict criteria for journals to be indexed in RISC. At the very beginning of the project it was decided to index any journal that considers itself to be scholarly, i.e. scope was deemed to be more important than selectivity. However, eLIBRARY.RU could reject indexing of, for example, politically engaged journals as well as magazines published for non-academic audience.

It is important to differentiate journals at the eLIBRARY.RU platform from journals indexed in RISC. Journal catalogue of eLIBRARY.RU now includes 12,975 active Russian periodicals, only 4,847 of them being indexed in RISC. RISC also indexes 541 foreign journals which are published mainly in the post-Soviet states.

In many research fields, especially in social sciences and humanities, scholarly output cannot be evaluated only by journal publications, it is also reflected in books, conference proceedings, dissertations, etc. In 2013 the book project was launched by eLIBRARY.RU and now the platform hosts both full texts and citation metadata for several types of non-periodical publications: monographs, reference books and dictionaries, textbooks and manuals, collections of articles, conference proceedings, dissertations and dissertation abstracts.

In 2015, a special subset of the best Russian journals indexed in the RISC was selected in order to create the Russian Science Citation Index on the international Web of Science platform in agreement with the Clarivate Analytics company (ex-Thomson Reuters). It has greatly expanded the presence of Russian journals in the international information space, especially for periodicals in the fields of social sciences and humanities, medicine, engineering and agriculture, which are underrepresented in the Web of Science and Scopus. At the same time an option of limiting citation analysis to the RISC Core (includes RSCI and Russian journals indexed in the Web of Science Core Collection or Scopus) was added to the RISC web interface. This allows users to compare publication and citation indicators calculated using the whole database with the similar counts based on its highest quality segment.

Along with the coverage growth and journal stratification, the other significant development of the bibliometric capabilities of RISC happened in 2011 with the introduction of the Science Index project. It aims to solve the problem of author identification, which is crucial for all citation databases. The Science Index service allows authors (since 2011) and organizations (since 2012) to actively maintain their publication and citation lists by themselves (Arefiev et al. 2012). 


\section{Content and coverage. Information sources}

There are 25 million documents at the eLIBRARY.RU platform with almost 260 million references. ${ }^{1}$ In terms of journals, there are about 6,500 titles at eLIBRARY.RU which are active, fully covered and indexed. About 5,500 of them provide their full texts for indexing, this enables extraction of the citation context (in the form of snippets), a unique feature of RISC unavailable in other citation databases. The journal content at eLIBRARY.RU is growing by approximately 300 periodicals per year (Fig. 1). If we add those titles which are covered selectively or sporadically, there are more than 60,000 journals in the eLIBRARY.RU catalogue, about 13,000 of them are active Russian journals.

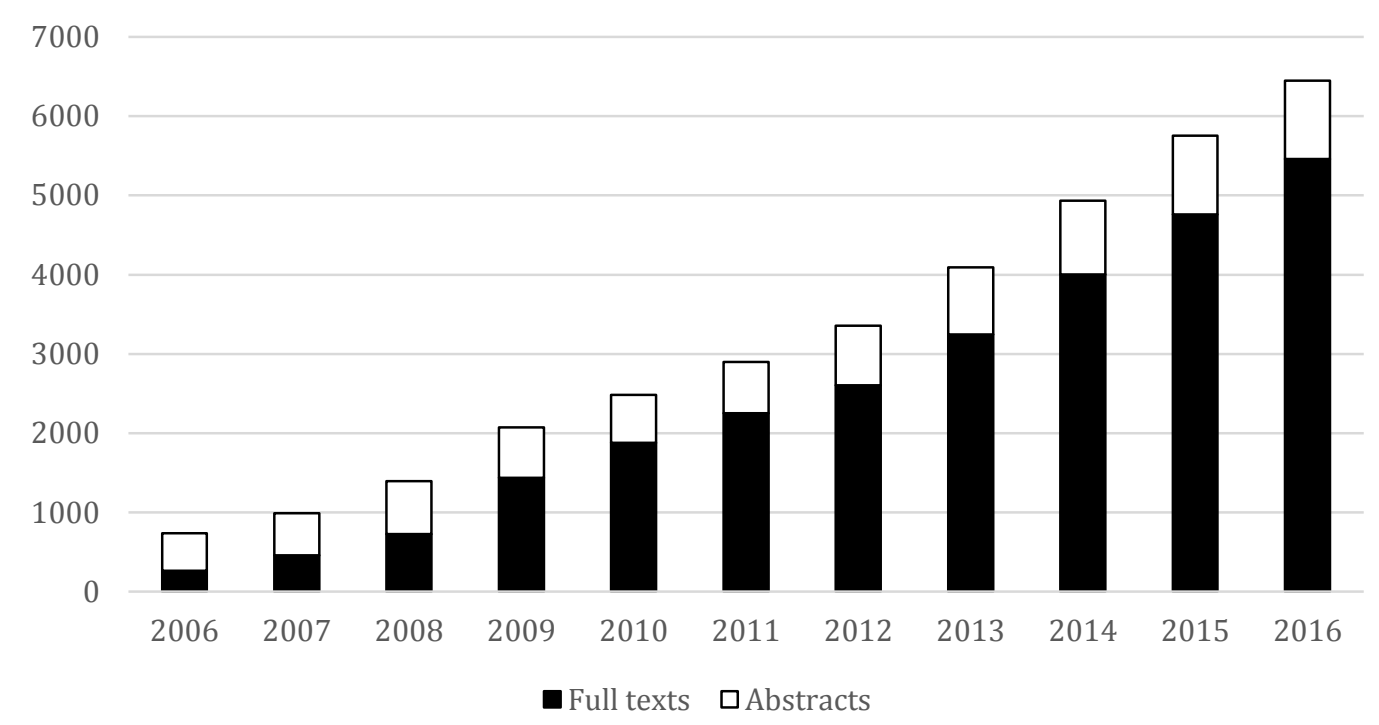

Fig. 1. Journals at eLIBRARY.RU with full texts and abstracts only

In 2010 an agreement was reached with the leading international scientific publisher Elsevier to import a subset of Scopus bibliographic and citation metadata into RISC. This subset includes all the publications affiliated to either Russia or other post-Soviet states (except Georgia and Baltic states), starting from 1996, and also all documents that cite these publications. Such a subset is updated twice a year and greatly enhances bibliometric capabilities of RISC. Since then RISC takes into account not only papers in Russian journals indexed in the database, but also Russian papers in foreign journals.

Books come to eLIBRARY.RU from several sources. The main venue are publishers or authors who sign agreements with eLIBRARY.RU. There are 1,750 contracts with 1,500 Russian and foreign publishers to deposit books to eLIBRARY.RU platform and more than 5,000 contracts with the authors to include their monographs. All the books uploaded by the authors are in full text in open access. Publishers also upload full texts, but have an option to restrict user access to them. However, these full texts are still searchable and provide citation snippets/contexts.

\footnotetext{
${ }^{1}$ All eLIBRARY.RU and RISC data are collected on 1 March 2017 and show the database content for that date.
} 
The main source of patent abstracts is the Federal Institute for Industrial Property, a subsidiary of Russian Patent Office.

Research project reports are mainly imported from the database of Russian Foundation for Basic Research and their full texts are available in open access.

Fig. 2 shows how the content of eLIBRARY.RU grows in terms of individual documents.

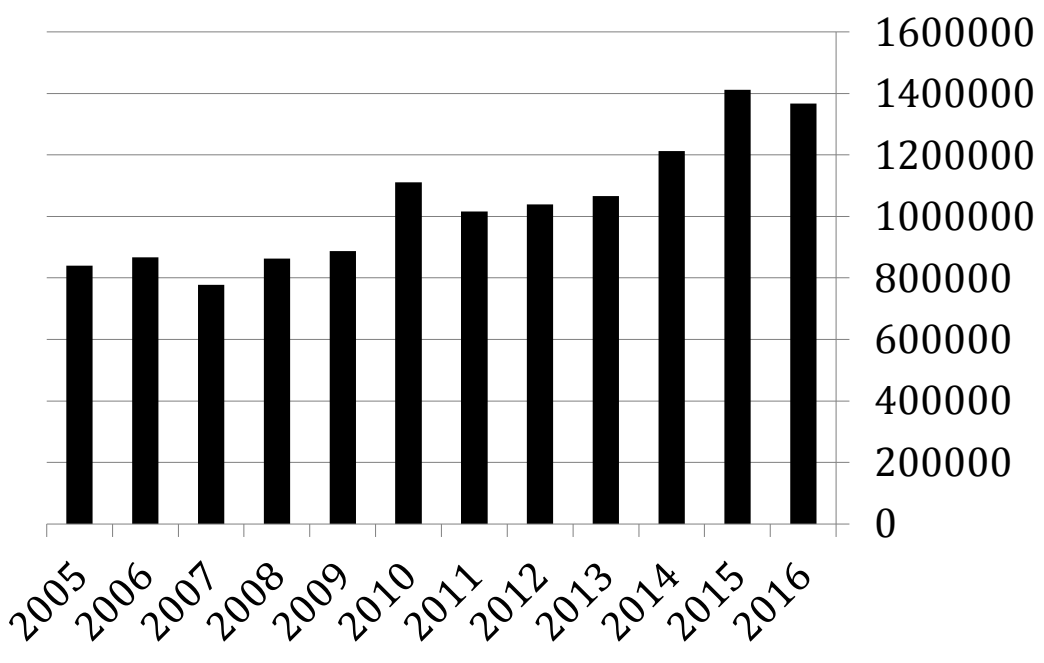

Fig. 2. Documents added to eLIBRARY.RU since RISC launch, by year

\section{Structure}

\section{Publication metadata}

Each document in RISC has its document type: research article, review, short communication, conference paper, letter, research report, book review, abstract, editorial, biographical item; monograph, article collection, textbook, dictionary or reference book, brochure, guidelines; conference proceedings; thesis; patent; research project report; preprint. Distribution of publications by the main document types is shown in Fig. 3.

Publication metadata may include different identifiers and subject indexes: DOI (Digital Object Identifier), PMID (PubMed Unique Identifier), UDC (Universal Decimal Classification), etc. Usually abstract and keywords in Russian and English are provided directly by publishers together with the references.

Publicly available web page for each document shows a wide range of bibliometric and altmetric indicators. Registered users may additionally find the link to citations received by a document in Google Scholar. They also may access link to the full text of a document at an external web site if the publisher provides this information. 


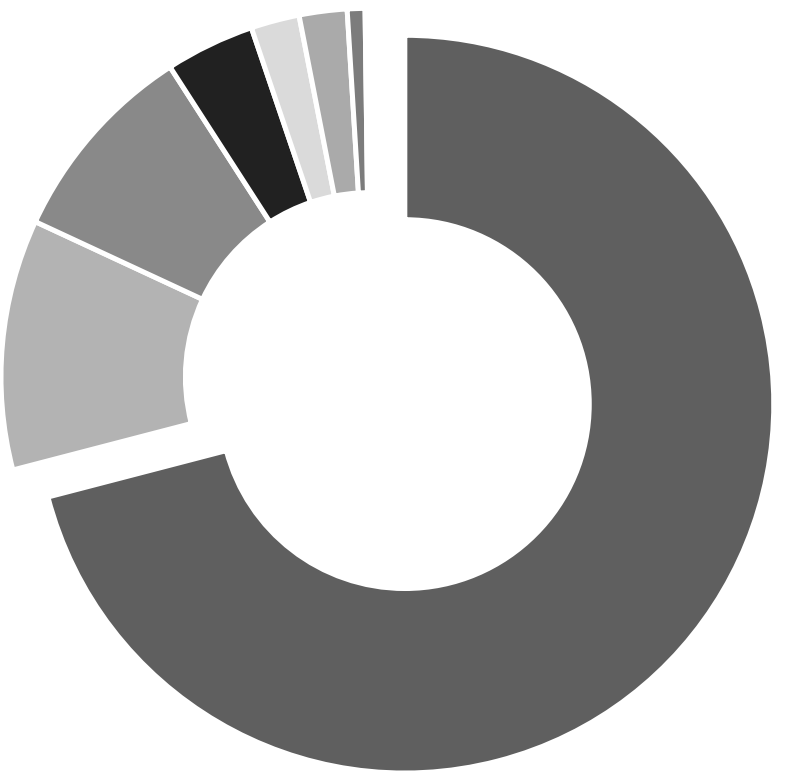

- Journal article (71\%, $17 \mathrm{mln})$

- Dissertation (10\%, $2.7 \mathrm{mln})$

- Conference paper (9\%, $2.2 \mathrm{mln})$

- $\operatorname{Book}(4 \%, 9.7 \mathrm{mln})$

Patent (2\%, $0.5 \mathrm{mln})$

- Book chapter (2\%, $0.5 \mathrm{mln})$

- Conference proceedings $(<1 \%, 0.19 \mathrm{mln})$

- Research report

- Preprint

Fig. 3. RISC publications, by document type

The bibliometric indicators include citation counts according to RISC, Web of Science and Scopus (the two latter received via corresponding APIs licensed from Clarivate Analytics and Elsevier), journal- and subject-normalized citation indicators, and other bibliometric information. Altmetrics include the number of record views, full text downloads from eLIBRARY.RU and the number of article sets created by users which include this document.

List of a document's references contains links to the cited items if they are indexed by eLIBRARY.RU. There are also citation context snippets for those cited items which full texts have been uploaded to eLIBRARY.RU. Once again, this unique feature is possible because of an important difference of RISC from major international citation databases: RISC is fully integrated with eLIBRARY.RU platform. Bibliographic and bibliometric information is combined with online electronic library, providing access to the full texts which are stored in the system together with metadata. At the moment more than 4,000 journals use eLIBRARY.RU as their full text hosting platform. Citation snippets is a unique feature of RISC comparing with Web of Science, Scopus or Google Scholar. Sometimes the context is crucial for a user, for example to decide whether a citation carries positive or negative connotation.

\section{Author profiles}

Another distinguishing feature of RISC is its system of author profiles. They are of two types: author-maintained (via a 'Science Index for authors' service, see below) and those that were generated automatically without any author input.

During the free registration in the 'Science Index for authors' the author enters his/her personal data, affiliations, name variants, research interests, list of journals where he/she has publications, ResearcherID, Scopus, ORCID identifiers. This helps to identify the authors in papers. Each 
registered author receives a SPIN-code, Scientist Personal Identification Number. The number of registered authors now exceeds 430,000.

For each author, RISC provides a list of all documents at eLIBRARY.RU where the scientist is identified as an author, editor or reviewer, a list of publications which cite this author, and a set of pre-calculated indicators of author's publication output. In accordance with modern bibliometric trends there are many metrics available: the number of papers and citations received by them, h-index, various bibliometric indicators for the last 5 years and distribution of publications by type, journal, coauthors, etc. There are also cross-links to author profiles in other databases (ResearcherID, ScopusID, ORCID, etc.).

The full list of author's publications also includes those his/her works which are not indexed at eLIBRARY.RU by themselves, but were found in the reference lists of the other indexed documents. This is another feature that distinguishes RISC from the Web of Science and Scopus, where such publications of an author can be found only by a special option of reference search as secondary documents. However, sometimes this feature may lead to double-counting of documents when they are cited slightly different in different reference lists. This is a problem which is yet to be solved by RISC team.

\section{Organization profiles}

Another unique feature of RISC is its system of organization profiles. Each organization can freely register at the platform to gain access to various free and paid services and subscriptions. For some prominent unregistered Russian academic organizations the profiles are created by RISC staff. All organizations are attributed to a specific country and a city, while Russian ones are also attributed to a region and a group (e. g. Federal universities, universities supported under the Russian government excellence ' $5-100$ ' initiative, research institutes of the different branches of the Russian Academy of Sciences, etc.).

RISC organization profile includes the general official information about organization and its publication output data.

Publication data include lists of (a) documents where this organization is among authors' affiliations; (b) all publications of authors during the period of their work in organization; and (c) all publications of current staff regardless of affiliation mentioned in their papers. These different options help to evaluate many aspects of research output in organization and its potential opportunities.

The section of publication activity analysis of the organization contains the total number of publications in RISC and citations received, number of authors affiliated with the organization and other characteristics. Additionally, the values of h-index, g-index and i- (or $\left.\mathrm{h}_{2-}\right)$ index (Kosmulski 2006; Rousseau et al. 2010) of organization are calculated. 
Publications of the last 5 years are analyzed in detail, including the distribution of publications across different journal groups (Russian journals, foreign journals, RSCI journals, etc.), their citedness in RISC, number of publications that were cited at least once, distribution of publications by OECD fields of science.

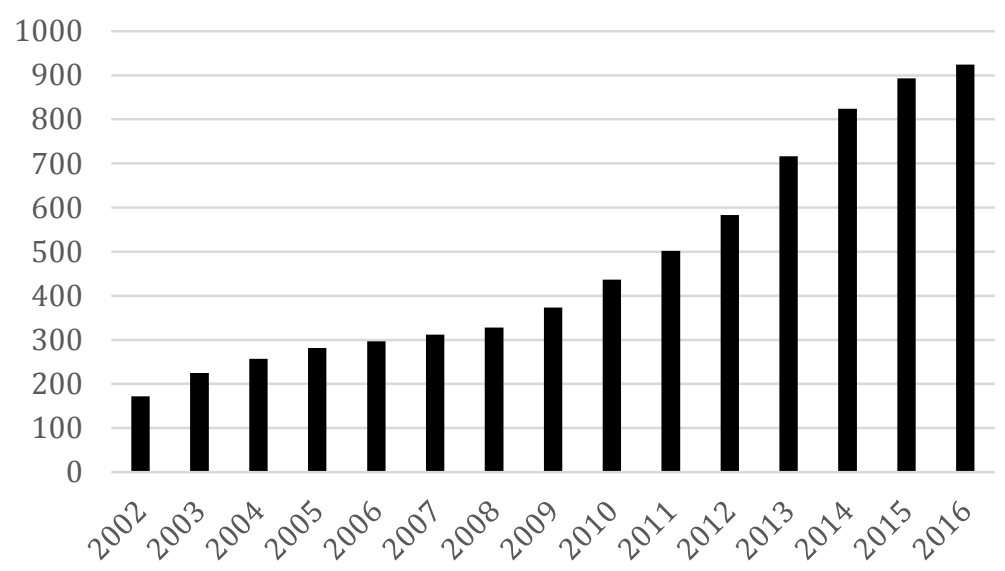

Fig. 4. Number of organizations registered at eLIBRARY.RU

Yearly bibliometric and altmetric indicators for the last 10 years are also available along with the distribution of papers across science disciplines, types of documents, organizations, authors, number of citations received, and number of coauthors.

The growth of the number of registered at eLIBRARY.RU organizations is shown in Fig. 4.

\section{Journal profiles}

Full journal information includes fields that enable journal search by multiple parameters: journal title, publisher, ISSN, country, subject area, language, indexed/not indexed in Web of Science or Scopus, availability of full texts and others.

A set of journal metrics is routinely calculated and published for each journal. The essential indicators are the number of documents and citations received during the last eight years and various statistical reports: distribution of indexed documents and citations to them by subject areas, keywords, authors, organizations, types of citing publications, etc.

\section{Access}

The access to RISC is free to all users after registration. RISC and eLIBRARY.RU are widely used not only in Russia. The dynamics of user registration and top- 25 countries by registered users are demonstrated in Figures 5 and 6 respectively. 


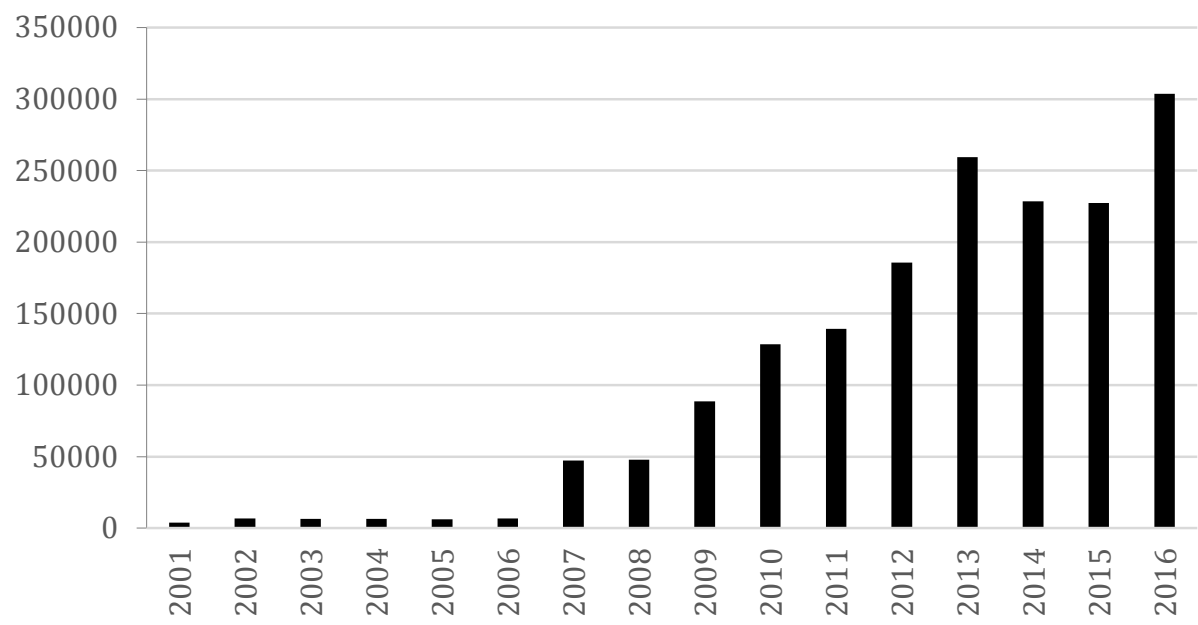

Fig. 5. Annual registration of users at eLIBRARY.RU

Users have free access to the full texts of open access journals and to services like creation of the sets of articles, journals, and authors. Almost 50\% of full-text journals in RISC are in open access. The access to the full text of the journals under subscription is available to the researchers and students from their institutional network if the institution is subscribed to these journals. Individual researchers and those from non-subscribing organizations may pay for access on per article basis.

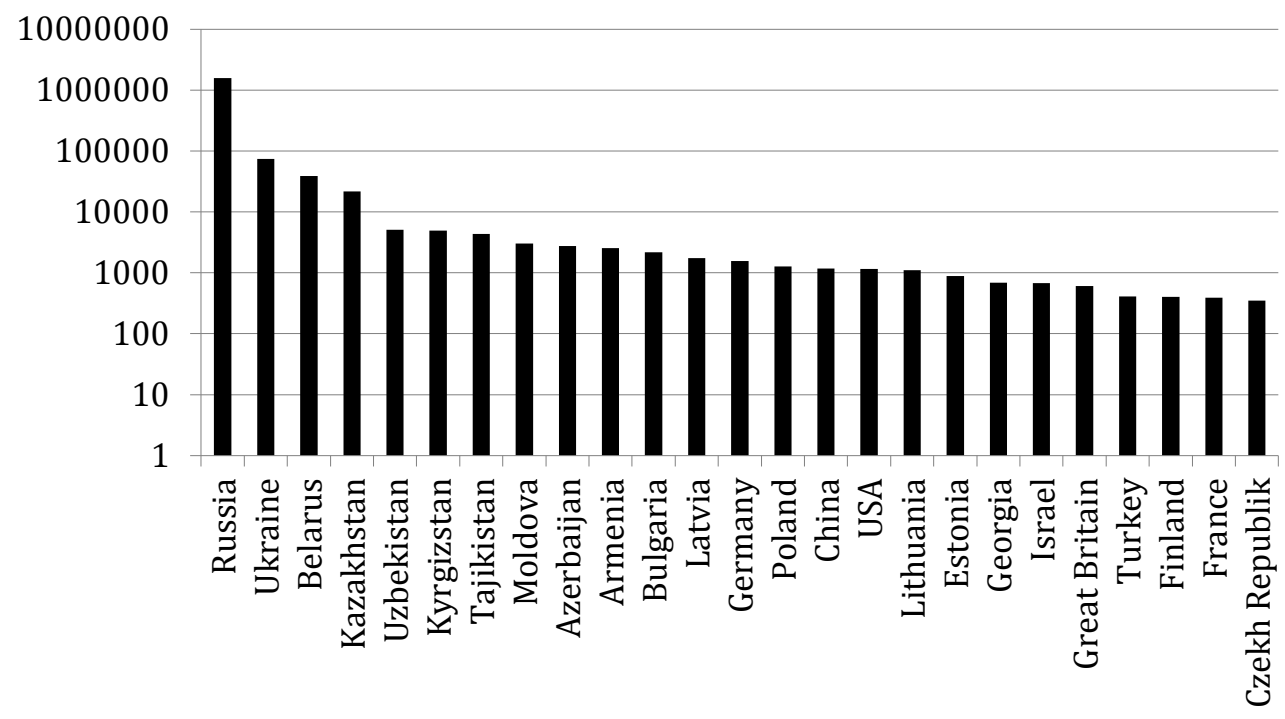

Fig. 6. Top-25 countries by number of registered users (logarithmic ordinate)

Registered users can add their own notes to a document, discuss it with other users and even evaluate the publication (a kind of post-publication peer review). These notes and evaluations are available to other users and can be seen in altmetrics section of a document's web page. 


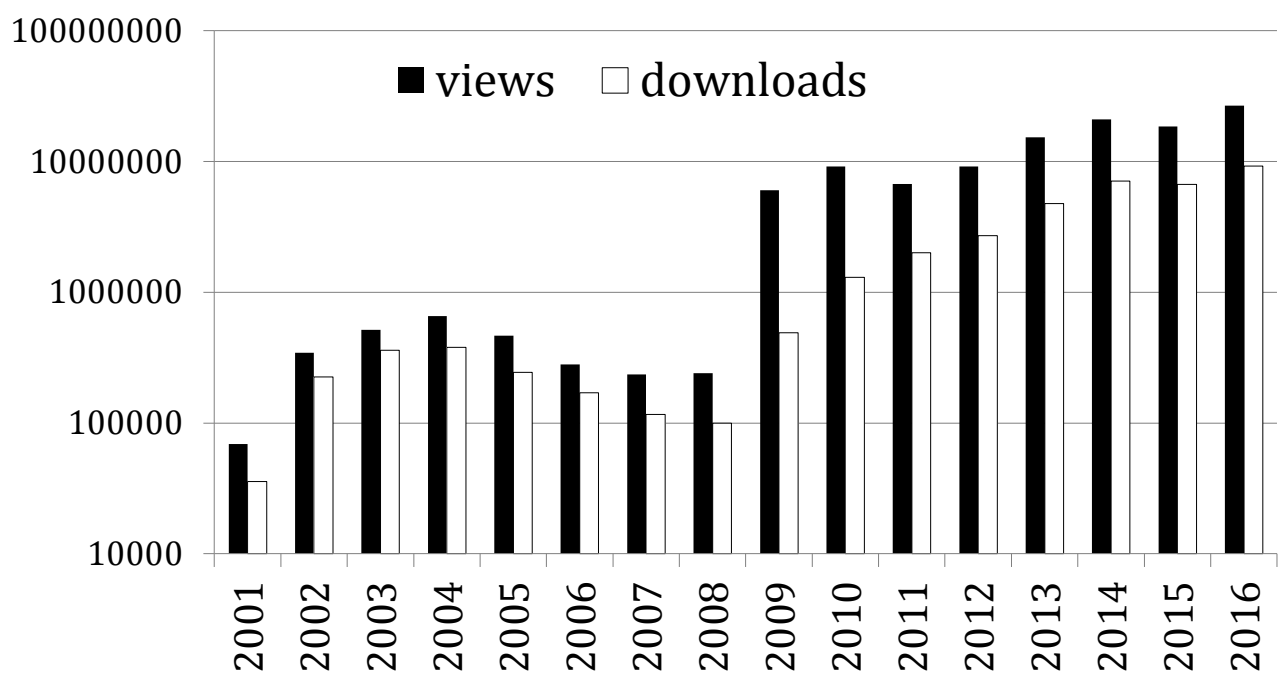

Fig. 7. Usage of eLIBRARY.RU. Record views and full text downloads (logarithmic ordinate)

The usage of the database is shown in Fig. 7. Remarkably, the ratio of views/downloads is rather stable over time.

\section{Analytics services}

RISC provides several standard types of analytical reports mentioned above - the analysis of publication output of an author, organization, and journal.

The registered user may create his own publication sets. The analysis of user-created publication sets is a summary of the total number of publications, the number of papers in peer-reviewed journals, the number of articles in journals included into the Web of Science or Scopus, the number of articles in journals included into the RISC core, the number of articles in journals included into the RSCI, the average impact factor of the journals where the articles were published, the average number of authors, the average number of publications per author, the total number of citations received by publications, the average number of citations per article, the number of articles cited at least once, the number of self-citations (cites from papers of the same user-created set), h-index of the publication set.

For advanced analytics the data from RISC can be exported in XML or via API. But this is a paid service.

\section{Additional services. User component. 'Science Index for authors and organizations'}

Authors' involvement into the correction of data in citation indexes is widely used. For example, correction of author profiles in Scopus is provided by Scopus through the authors' feedback. An author can send a request to merge his multiple profiles in Scopus, to add missing publications or delete from his profile publications of another author with the same name.

RISC launched the same service for authors in 2011, for organizations in 2012. 
'Science Index for authors' is an advanced service that enables an author not only to create or change his profile in eLIBRARY.RU, but also add publications or citations that are not linked to it. The service also helps to disambiguate different authors.

There are about 450 thousand scholars registered in 'Science Index for authors.' More than 400 thousand of them are from Russia.

'Science Index for organizations' provides additional possibilities for correction and analysis of publication lists. Official representative of an organization can perform various actions with lists of publications and citations on behalf of the authors from his institution. The position of each author and the period of his work in organization may be added into the database. Even the complex organizational structure of an institution can be created by an official representative and uploaded to a database, this enables the analysis of publication output for departments, labs, research groups, etc.

One of the important options of 'Science Index for organizations' service is a possibility to revise links between documents and to match references in a database to publications of an institution. This helps to manually correct some errors occurred due to mistakes in references: year or volume/issue of the journal, publication title, authors. This also improves the overall quality of the database. The same issues were discussed in literature, for example by Garfield (1974).

Corrections proposed by organizations are finally verified by eLIBRARY.RU bibliographers.

There are more than 900 subscribers to 'Science Index for organizations', about of half of them are higher education organizations, about half of them are research institutes.

\section{Journal metrics}

Like all citation databases, RISC allows to evaluate the quality of academic journals by citation metrics. There is a whole range of different indicators available.

First, there is a set of 'impact-factor-like' indicators that show the average number of citations per document in a journal. Two-year and five-year impact factors with or without journal selfcitations are calculated for each journal in RISC. Additionally, the two-year impact factor is calculated which includes citations not only from journals, but from all document types in RISC, so the share of non-journal publications in the total number of citations to journal's papers may be assessed.

Impact factor should not be considered as an only proxy to a quality of an academic journal. For example, this index can be inflated by self-citations from the same journal or citations from the journals which organize a closed mutual citation network. A good analysis of such 'citation cartels' for Eastern European countries is provided by Teodorescu and Andrei (2014). There is even a case when a Lithuanian journal with low international visibility was ranked third(!) in the economics category of Journal Citation Reports database (Gibson et al. 2012). 
Therefore, impact factor is used along with other indicators calculated in RISC. Share of journal self-citations and Herfindahl index for citing journals were chosen. Their combination helps to detect potentially problematic citation practices. High values of these parameters may indicate that a significant proportion of cites to the journal come either from its own papers or from a very limited number of other sources.

In eLIBRARY.RU Herfindahl index is also used for organizations mentioned as an author's affiliation. It helps to assess if the journal publishes the papers by authors from many institutions, not from a closed community.

\section{Science Index journal indicator}

A special complex journal indicator is calculated in RISC, 'Science Index journal indicator'. It combines various aspects of bibliometric journal quality by using several consecutive normalization procedures.

Its methodology includes normalization by OECD subject categories, by average size of reference lists in the science field, by chronological distribution of citations and their share leading to papers included to eLIBRARY.RU database. It partly resembles the SNIP indicator (Moed 2010), but differs by citation window (Science Index uses five years instead of three in SNIP). Herfindahl index is also used in the methodology. It assesses how diverse are citations the journal receives and has its weight in the 'Science Index journal indicator'.

This methodology is an attempt to make cross-disciplinary comparison and to rank journals more accurately. ${ }^{2}$

\section{Journal selection for Russian Science Citation Index at the Web of Science platform}

Joint project of the Clarivate Analytics with eLIBRARY.RU was accomplished to select the most influential Russian academic journals for a database Russian Science Citation Index (RSCI) which is available at the Web of Science platform. This is an 'additional' database, like other national citation indexes at Web of Science, and is not a part of the Web of Science Core Collection. However, there are also Russian journals which are included into RSCI and at the same into other Web of Science Core Collection databases.

Selection of the best journals from RISC (Russian Index of Science Citation, at eLIBRARY.RU) for RSCI (Russian Science Citation Index, at Web of Science) was made both by bibliometric evaluation and expert decisions. More than 30,000 experts were invited, more than 12,500 responded with 240,000 marks given to journals.

Finally, 652 leading journals were selected. Fig. 8 shows their distribution across fields of science compared to all RISC database titles. There is a sharp change in the share for some

\footnotetext{
${ }^{2}$ Detailed description of the methodology is published, but as of January 2018 only in Russian: http://elibrary.ru/help_title_rating.asp
} 
subject areas. For example, 29\% share of social science journals in RISC has become only $15 \%$ for the selection of the best of them in RSCI. On the contrary, other fields such as biology, Earth sciences and, especially, physics/astronomy/chemistry demonstrate a steep increase in their presence in the selected set, their percentage has more than doubled. ${ }^{3}$

\section{Distribution of subject areas in RISC/RSCI}

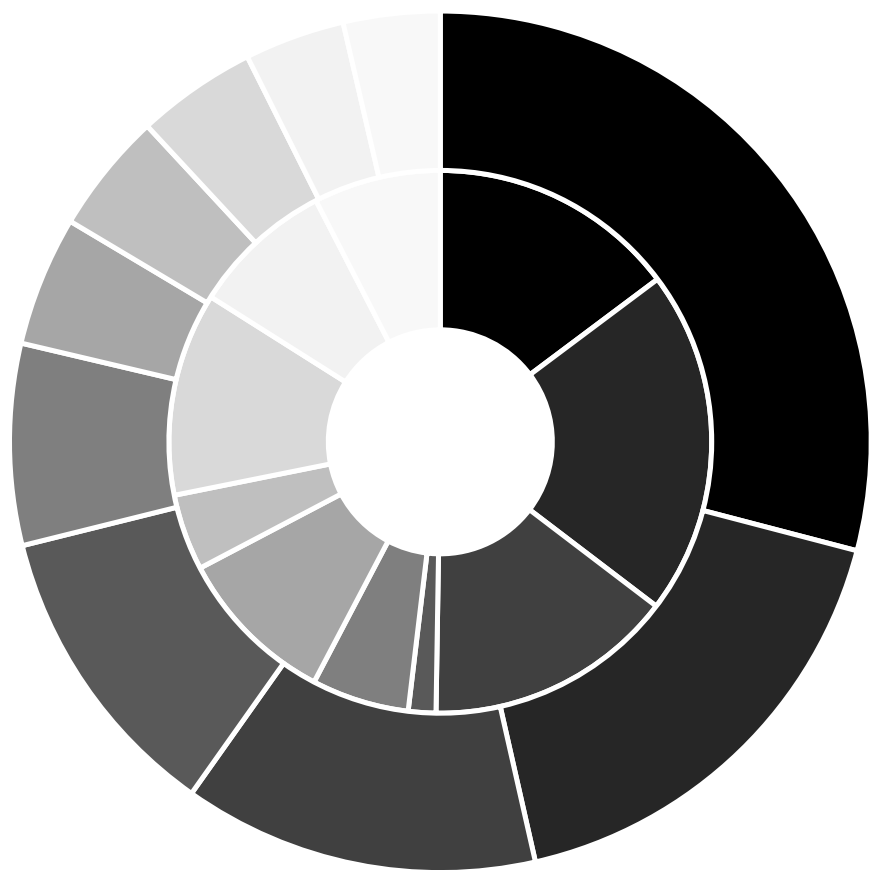

- Social sciences

- Engineering and technology

- Medical and health sciences

- Multidisciplinary

- Humanities

- Mathematics, computer and information sciences

- Agricultural sciences

Physical sciences, astronomy, chemical sciences

Biological sciences

Earth and related environmental sciences

Fig. 8. Distribution of journals by subject areas in RISC (outer circle) compared to RSCI (inner circle). A journal can be attributed to one or more subject areas

As a result, the disciplinary structure of these two databases is quite different. Interestingly, the selected set of the best journals visually has become more balanced (multidisciplinary category is an exception). Exact calculations prove it: Gini coefficient (the measure of the inequality of distributions) for RISC is 0.41 while for RSCI set of subject areas it is significantly lesser, 0.25 (multidisciplinary journals are omitted in both cases).

Journal selection for RSCI has started the total re-evaluation of journals at eLIBRARY.RU platform. More than 300 journals have been finally excluded from RISC due to different problems with peer review process, plagiarism, etc.

As of January 2018, analytics can be performed at eLIBRARY.RU on the basis of different groups of publications:

- All publications at eLIBRARY.RU;

- Publications chosen for RISC;

\footnotetext{
${ }^{3}$ An extreme change in multidisciplinary category in Fig. 8 most probably may be ascribed to different definitions of multidisciplinarity in the databases.
} 
- Papers in journals included into RISC Core (those indexed in Web of Science Core Collection, Scopus, or selected for RSCI on Web of Science platform);

- Papers in journals from Higher Attestation Commission list ('VAK journals'), that is journals approved by Ministry of Education and Science during the dissertations/scientists certification.

Fig. 9 shows publications/citations indicators for different segments of eLIBRARY.RU in 2016. The first bar shows those eLIBRARY.RU journals which are also indexed in Web of Science Core Collection and/or Scopus database. The next are journals included to RSCI but not indexed in Web of Science Core Collection databases or Scopus. Next are VAK journals (see definition above) not included into the upper bars and, finally, those which do not fall into any previous category.

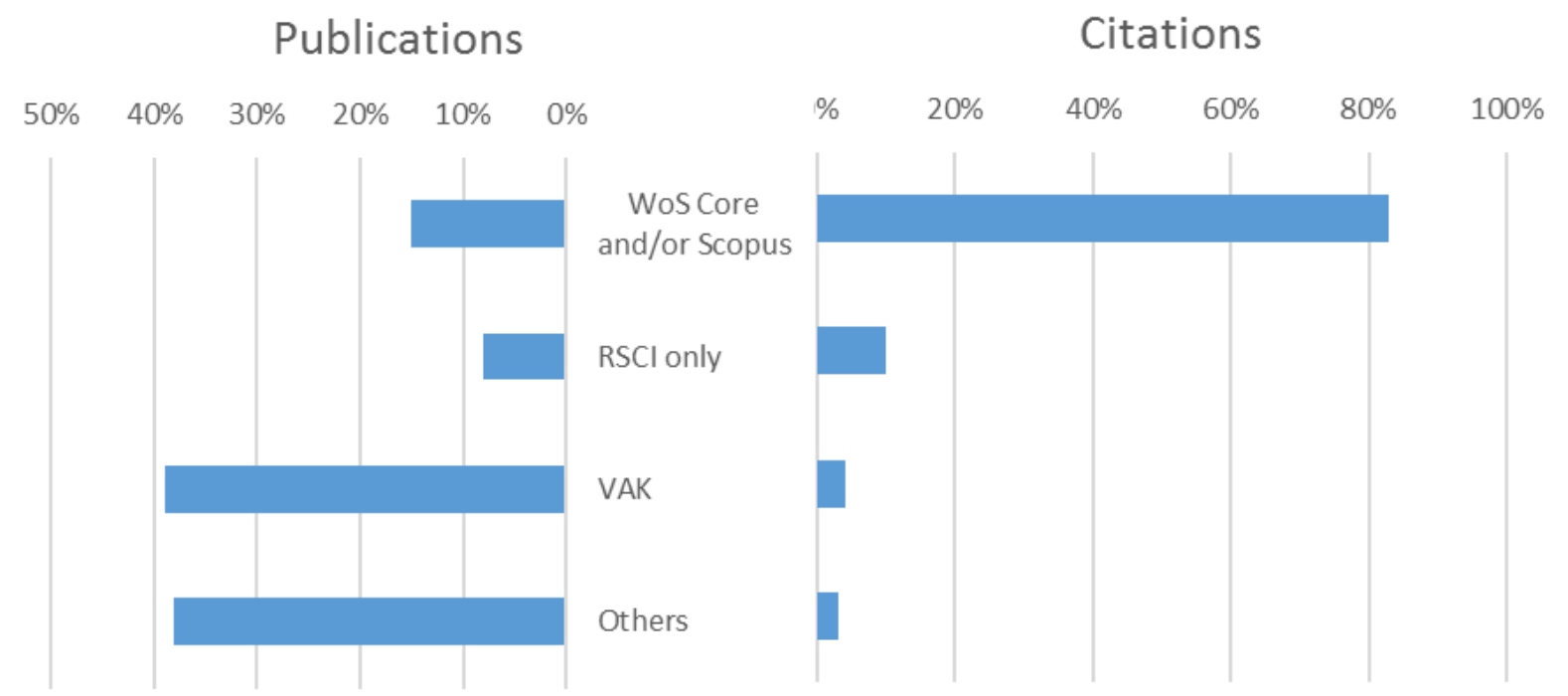

Fig. 9. Distribution of publications and citations in different sources indexed at eLIBRARY.RU (WoS Core is the Web of Science Core Collection)

The sharp inequality of citation distribution is obvious. The RISC Core, which is the sum of the two upper bars, contains only 23\% of papers, but attracts $93 \%$ of citations. Garfield (1990) observed the similar skewness for the Science Citation Index (he found 21/83 proportion). At the same time this is a strong argument to suppose that journals for RISC Core were defined properly.

\section{Conclusion}

Russian journals are aggregated now at the eLIBRARY.RU platform. The first and probably the most important point is that Russian journals have now become visible. Regional journals from distant regions now are available for researchers, at minimum at the level of tables of contents/abstracts.

One of the main functions of science is communication (Merton 1968). As sociologists of science think, if a brilliant research is not communicated to others, it is not a scientific achievement. So the creation of eLIBRARY.RU makes Russian science much better. We may 
even say that from classic sociological point of view the launch of such a database often turns non-science to science in Russia. Now a researcher from Moscow has a chance to communicate with a researcher from Vladivostok (more than $6,400 \mathrm{~km}$ distance), this is to say be alerted about his papers and be informed of his current research published in a local Vladivostok journal. This is very important for a science in a spatially large country. And many of these papers can be read in full text at eLIBRARY.RU.

Moreover, the platform also helps to assess citedness of journals and their scientific level. One may make reliable evaluation of the quality of indexed journals, publication activity of authors and organizations across all Russia.

Today RISC is widely used for the applied analysis of Russian institutes and universities (Zibareva and Parmon, 2012; Moskovkin et al. 2017; Nemtsov et al. 2015). Most probably, this trend will become more pronounced in the future.

\section{Acknowledgements}

The shorter version of the paper was presented at ISSI 2017 conference in Wuhan, China. We are grateful to Gennadiy Eremenko, CEO of eLIBRARY.RU, for his invaluable help. We thank Natalia Maksimova, Higher School of Economics Library Director, for arranging HSE access to bibliometric databases and her continuous support. We also thank Vasiliy Pislyakov for his help in data mining.

\section{References}

Arefiev, P., Eremenko, G., \& Glukhov, V. (2012). Russian Index of Science Citation-the instrument for research evaluation. Bibliosphera, 5, 66-71.

Eremenko, G. (2003). Science Electronic Library is 3 years old: The results and main opportunities for further development. Electronic libraries, 6(1), 39-51.

Garfield, E. (1974). Errors - Theirs, Ours and Yours. Current Contents, 25 (June 19), 5-6.

Garfield, E. (1990). How ISI selects journals for coverage: Quantitative and qualitative considerations. Current Contents, 22 (May 28), 185-193.

Gibson, J., Anderson, D. L., \& Tressler, J. (2012). Which Journal Rankings Best Explain Academic Salaries? Evidence from the University of California. Working Paper in Economics 10/12. University of Waikato. Retrieved 08 January, 2018, from ftp://wmswebprod1.mngt.waikato.ac.nz/RePEc/wai/econwp/1210.pdf.

Jin, B., \& Wang, B. (1999). Chinese Science Citation Database: Its construction and application. Scientometrics, 45(2), 325-332.

Kosmulski, M. (2006). "I"-A bibliometric index. Forum Akademickie, 11, 31.

Merton, R. K. (1968). The Matthew effect in science. Science, 3810, 56-63.

Moed, H. F. (2010). Measuring contextual citation impact of scientific journals. Journal of Informetrics, 4(3), 265-277.

Moskovkin, V. M., $\quad$ Liu, Y., $\quad$ Pupynina, E. V., $\quad$ Balabanova, T. V., $\quad \& \quad$ Peresypkin, A. P. (2017). Methodological aspects of assessing regional publication activity and citations: The case of the RF Central Federal District universities. Journal of Fundamental and Applied Sciences, 9(7S), 10891102.

Negishi, M., Sun, Y., \& Shigi, K. (2004). Citation Database for Japanese Papers: A new bibliometric tool for Japanese academic society. Scientometrics, 60(3), 333-351. 
Nemtsov, A. V., Trushchelev, S. A., \& Krasnov, V. N. (2015). Publishing activity of Russian research institutes in the field of psychiatry and addictology in 2006-2013. Zhurnal Nevrologii i Psikhiatrii Imeni S. S. Korsakova, 1, 85-90.

Pajić, D. (2015). The Serbian Citation Index: Contest and Collapse. Proceedings of ISSI conference 2015, (Istanbul, Turkey) (pp. 604-605).

Pislyakov, V. (2007). Why should we create national citation indexes? Science and Technical Libraries, iss. 2, 65-71.

Rousseau, R., Yang, L., \& Yue, T. (2010). A discussion of Prathap's $\mathrm{h}_{2}$-index for institutional evaluation with an application in the field of HIV infection and therapy. Journal of Informetrics, 4(2), 175184.

Teodorescu, D., \& Andrei, T. (2014). An examination of "citation circles" for social sciences journals in Eastern European countries. Scientometrics, 99(2), 209-231.

Tretyakova, O. V. (2015). Development of national citation index as a condition for the formation of a system to evaluate scientific research performance. Economic and social changes: facts, trends, forecast, 1(37), 230-245.

Šipka, P. (2005). The Serbian citation index: context and content. Proceedings of ISSI 2005 - The 10th International Conference of the International Society for Scientometrics and Informetrics (Stockholm, Sweden) (pp. 710-711). Stockholm: Karolinska University Press.

Su, X., Deng, S., \& Shen, S. (2014). The design and application value of the Chinese Social Science Citation Index. Scientometrics, 98(3), 1567-1582.

Wouters, P., Thelwall, M., Kousha, K., Waltman L., de Rijcke, S., Rushforth, A., \& Franssen, T. (2015). The Metric Tide: Literature Review (Supplementary Report I to the Independent Review of the Role of Metrics in Research Assessment and Management). HEFCE. Retrieved 12 December, 2017, from http://www.dcscience.net/2015_metrictideS1.pdf.

Wu, Y., Pan, Y., Zhang, Y., Ma, Z., Pang, J., Guo, H., Guo, H., Xu, B., \& Yang, Z. (2004). China Scientific and Technical Papers and Citations (CSTPC): History, impact and outlook. Scientometrics, 60(3), 385-397.

Yadav, B., \& Yadav, M. (2014). Resources, facilities and services of the Indian citation index (ICI). Library Hi Tech News, 31(4), 21-29.

Ye, J. (2014). Development, significance and background information about the "Chinese Book Citation Index" (CBkCI) demonstration database. Scientometrics, 98(1), 557-564.

Zibareva, I., \& Parmon, V. (2012). Ranking institutes of the Russian academy of sciences by the Russian science citation index: The case of chemical research institutes. Herald of the Russian Academy of Sciences, 82(5), 363-372. 